\title{
The prevalence and prognostic significance of KRAS mutation subtypes in lung adenocarcinomas from Chinese populations
}

\author{
Difan Zheng ${ }^{1,2, *}$ \\ Rui Wang ${ }^{1,2, *}$ \\ Yang Zhang ${ }^{1,2}$ \\ Yunjian $\operatorname{Pan}^{1,2}$ \\ Xinghua Cheng ${ }^{3}$ \\ Chao Chengl,2 \\ Shanbo Zheng ${ }^{1,2}$ \\ Hang Li, ${ }^{1,2}$ \\ Ranxia Gong ${ }^{1,2}$ \\ Yuan $\mathrm{Li}^{2,4}$ \\ Xuxia Shen ${ }^{2,4}$ \\ Yihua Sun ${ }^{1,2}$ \\ Haiquan Chen ${ }^{1-3,5}$ \\ 'Department of Thoracic Surgery, \\ Fudan University Shanghai Cancer \\ Center, ${ }^{2}$ Department of Oncology, \\ Shanghai Medical College, Fudan \\ University, ${ }^{3}$ Shanghai Chest Hospital, \\ Shanghai Jiao Tong University, \\ ${ }^{4}$ Department of Pathology, Fudan \\ University Shanghai Cancer Center, \\ ${ }^{5}$ Institutes of Biomedical Sciences, \\ Fudan University, Shanghai, People's \\ Republic of China \\ *These authors contributed equally \\ to this work
}

Correspondence: Haiquan Chen; Yihua Sun

Department of Thoracic Surgery, Fudan University Shanghai Cancer Center, 270 Dong-An Road, Shanghai 200032, People's Republic of China Tel +86 2I 64175590 Fax +86 2I626865II Email hqchen I@yahoo.com; sun_yihua76@hotmail.com
This article was published in the following Dove Press journal:

OncoTargets and Therapy

22 February 2016

Number of times this article has been viewed

Background: We performed this retrospective study to identify the prevalence of $K R A S$ mutation in Chinese populations and make a comprehensive investigation of the clinicopathological features of KRAS mutation in these patients.

Patients and methods: Patients from 2007 to 2013 diagnosed with primary lung adenocarcinoma who received a radical resection were examined for KRAS, EGFR, HER2, BRAF mutations, and $A L K, R E T$, and ROS1 fusions. Clinicopathological features, including sex, age, tumor-lymph node-metastasis stage, tumor differentiation, smoking status, histological subtypes, and survival information were analyzed.

Result: KRAS mutation was detected in 113 of 1,368 patients. Nine different subtypes of $K R A S$ mutation were identified in codon 12, codon 13, and codon 61. KRAS mutation was more frequently found in male patients and former/current smoker patients. Tumors with $K R A S$ mutation had poorer differentiation. Invasive mucinous adenocarcinoma predominant and solid predominant subtypes were more frequent in KRAS mutant patients. No statistical significance was found in relapse-free survival or overall survival between patients with KRAS mutation and patients with other mutations.

Conclusion: In Chinese populations, we identified KRAS mutation in $8.3 \%(113 / 1,368)$ of the patients with lung adenocarcinoma. KRAS mutation defines a molecular subset of lung adenocarcinoma with unique clinicopathological features.

Keywords: KRAS, NSCLC, surgery, prognosis

\section{Introduction}

Lung cancer remains the leading cause of cancer deaths worldwide. ${ }^{1}$ In the past few decades, lung cancer was binary classified into small-cell lung cancer and non-smallcell lung cancer (NSCLC). Nowadays, however, the discovery of the driver mutations and related target therapies has changed the way scientists and doctors are treating this disease. The 5-year survival rate of lung cancer remains low (only 16.8\%) when taking all stages into account; ${ }^{2}$ some selected patients still benefit a lot from targeted therapy. ${ }^{3-6}$

$K R A S$ protein functions as a GTPase that is essential for cell signaling. When extracellular stimuli, such as epidermal growth factor (EGF), activates the KRAS protein; the activated $K R A S$ subsequently binds to a spectrum of downstream effector targets, and performs the signal transduction. ${ }^{7}$ Mutant $K R A S$ protein, however, is stimulus independent. It can persistently activate the downstream effectors, such as the RAFMEK-ERK cascade and PI3K-AKT-mTOR pathway, regardless of the absence of the upstream stimuli, and ultimately impact cell proliferation, survival, and metastasis. ${ }^{8}$

submit your manuscript | www.dovepress.com 
In NSCLC, the prevalence of KRAS mutation is $15 \%-32 \%$ according to the latest data. ${ }^{9}$ The mutation frequency varies among different ethnic populations. A relatively low frequency is identified in Asian and Latin America populations (15\%-20\%) compared with European population $(20 \%-30 \%) .{ }^{10}$ This imbalance may partially attribute to the high frequency of EGFR mutation in Asian and Latin America populations, which are mutually exclusive with $K R A S$ mutation, or other associated risk factors, such as tobacco use. Mutant $K R A S$ gene is predominantly found in adenocarcinoma histology. In squamous histology tumors, it is a rare event. Many studies suggest that $K R A S$ mutation is closely associated with cigarette smoking. ${ }^{11}$ Current or former smokers have a higher frequency of $K R A S$ mutations than never smokers. ${ }^{11}$ Further analysis reveals that different smoking status leads to a different $K R A S$ point mutation profile. Never smokers were significantly more likely than former or current smokers to have a transition mutation $(\mathrm{G} \rightarrow \mathrm{A})$ rather than the transversion mutations known to be smoking-related $(\mathrm{G} \rightarrow \mathrm{T}$ or $\mathrm{G} \rightarrow \mathrm{C} ; P<0.0001){ }^{12}$

In 1990, Slebos et al first reported that KRAS codon 12 point mutation was a strong and unfavorable prognostic factor based on an analysis of 69 lung adenocarcinoma patients. ${ }^{13}$ Since then, controversy remains on its prognostic significance for predicting the survival time in lung cancer. In 2005, a systematic review and meta-analysis revealed that $K R A S$ mutation was of poor prognostic significance for survival in patients with NSCLC. Recently, a meta-analysis of 12 randomized trials confirmed that KRAS mutation was associated with poor prognosis for NSCLC, particularly for those with advanced stage disease or who received second or later line therapy or treated with EGFR TKIs. ${ }^{14}$

Although many studies analyzed the prevalence, clinicopathological features, and prognosis of KRAS mutation, contradictory conclusions have appeared and controversy remains. ${ }^{9-11}$ Besides, data from Asian population were insufficient. Therefore, here, we performed the largest retrospective study of $K R A S$ mutation in patients with lung adenocarcinoma in an Asian ethnic group - to identify the prevalence of KRAS mutation in Chinese population, describe the clinicopathological features of these patients, and analyze their survival with other types of gene mutations.

\section{Methods}

\section{Patients and samples}

Patients were selected retrospectively at the Department of Thoracic Surgery, Fudan University Shanghai Cancer Center from 2007 to 2013. Patients who received neoadjuvant chemotherapy were excluded. All the qualified patients had primary lung cancer and received a radical resection. (Patients with stage I to stage III underwent complete surgical excision. As for stage IV patients, all of them had solitary or surgically resectable metastasis. Both the primary lesion and the metastasis were surgically removed through one or two surgeries). Two independent pathologists (Yuan Li and Xuxia Shen) pathologically confirmed their tumor samples as lung adenocarcinoma according to the new WHO classification of lung tumors. Tumor tissues and normal para-carcinoma tissues were sampled just after the surgical resection and immediately stored in liquid nitrogen.

This study was conducted in line with the Declaration of Helsinki and approved by the Institutional Review Board of the Fudan University Shanghai Cancer Center. Written informed consent was obtained from all patients to allow their biological samples to be genetically analyzed. The experimental protocol of this study was performed strictly in accordance to the guidelines.

\section{RNA extraction}

Total RNA was extracted from the tumor and normal paracarcinoma tissue as per standard protocols (RNeasy Mini Kit, Qiagen, Hilden, Germany), respectively. Total RNA samples were reverse transcribed into complementary DNA using a Revert Aid First Strand cDNA Synthesis Kit (Fermentas, St Leon-Rot, Germany).

\section{Mutation analysis}

$K R A S$ (exons 2-3), EGFR (exons 18-22), HER2 (exons 18-21), and $B R A F$ (exons 11-15) were amplified by polymerase chain reaction (PCR) using KOD-plus DNA polymerase and cDNAs. ${ }^{15}$ (The primers are listed in Table S1). Direct dideoxynucleotide method sequencing was performed to analyze the gene mutations. A combined strategy of reverse transcriptase PCR and quantitative realtime PCR was performed to detect ALK, RET, and ROS1 fusions. Fluorescent in situ hybridization was used as a validation for these fusion genes. ${ }^{16-18}$

\section{Clinicopathological features}

Clinical information including sex, age at diagnosis, pathologic tumor-lymph node--metastasis stage (according to the seventh edition of the lung cancer staging classification system) tumor differentiation, and smoking status was collected. Histologic subtypes of adenocarcinoma were confirmed based on the newest International Association for the Study of Lung Cancer/ American Thoracic Society/European Respiratory Society multidisciplinary classification of lung adenocarcinoma. Survival and tumor relapse information was collected every 3 or 6 months after surgery in the clinic or by telephone. 


\section{Statistical analysis}

Pearson's chi-squared test or Fisher's exact test (when the count in any cell of a contingency table was less than required) was used on categorical variables. The KaplanMeier method was performed to estimate the survival curve. Log-rank test was performed to compare the survival data. Multivariate analysis (Cox regression analysis) was used to assess the effect of covariates on relapse-free survival (RFS) and overall survival. We used SPSS for Windows (version 19.0) (IBM Corporation, Armonk, NY, USA) to analyze data. All tests were two-tailed and a $P$-value $<0.05$ indicated statistical significance.

\section{Results}

\section{Clinicopathological features}

A total of 1,368 patients from 2007 to 2013 were qualified in this retrospective study cohort. The average age was 59.7 years, ranging from 22.4 to 84.1 years. There were
$623(45.5 \%)$ males and 745 (54.5\%) females. Of them, 369 were current smokers $(27.0 \%), 79$ were former smokers (5.8\%), and 920 were never smokers $(67.2 \%)$. The numbers of patients in pathological tumor-lymph node-metastasis stages I to IV were 749 (54.8\%), 167 (12.2\%), 425 (31.0\%), and $27(2.0 \%)$, respectively. In adenocarcinoma subtypes, acinar predominant $(43.1 \%)$ was the most frequent, followed by solid predominant $(18.6 \%)$, and papillary predominant (15.6\%). More detailed clinicopathological features are summarized in Table 1.

\section{Gene mutation spectrum}

There were 837 patients who harbored $E G F R$ mutation, accounting for approximately $60 \%$ of the population. KRAS mutation was detected in $113(8.3 \%)$ of all the patients. Thirty-two (2.3\%) patients had HER2 mutation, 20 (1.5\%) patients had $B R A F$ mutation, and $102(7.5 \%)$ patients had $A L K, R E T$, or ROS1 fusion genes (Figure 1). No patients

Table I Clinicopathological features of I,368 lung adenocarcinoma patients

\begin{tabular}{|c|c|c|c|c|c|c|}
\hline Variables & KRAS & EGFR & HER2 & BRAF & ALKIRETIROSI & WT and others \\
\hline Mutation type, n (\%) & II $3(8.26)$ & $837(61.18)$ & $32(2.34)$ & $20(1.46)$ & $102(7.46)$ & $264(19.30)$ \\
\hline \multicolumn{7}{|l|}{ Age, years } \\
\hline$<60, \mathrm{n}(\%)$ & $63(56)$ & 414 (49) & $23(72)$ & II (55) & $64(73)$ & 116 (44) \\
\hline$\geq 60, \mathrm{n}(\%)$ & $50(44)$ & $423(5 \mathrm{I})$ & $9(28)$ & $9(45)$ & $38(27)$ & $148(56)$ \\
\hline Mean & 59.46 & 59.95 & 54.43 & 57.76 & 56.66 & 60.87 \\
\hline Standard deviation & 9.04 & 9.96 & 9.85 & 9.47 & 9.81 & 10.72 \\
\hline \multicolumn{7}{|l|}{ Sex } \\
\hline Male, n (\%) & $90(80)$ & $303(36)$ & $2(6)$ & $12(60)$ & $39(6)$ & I77 (67) \\
\hline Female, n (\%) & $23(20)$ & $534(64)$ & $30(94)$ & $8(40)$ & $63(94)$ & 87 (33) \\
\hline \multicolumn{7}{|l|}{ Smoker } \\
\hline Never, n (\%) & $34(30)$ & $657(78)$ & $32(100)$ & $8(40)$ & $75(100)$ & II4 (43) \\
\hline Current/former, $\mathrm{n}(\%)$ & $79(70)$ & $180(22)$ & $0(-)$ & $12(60)$ & $27(-)$ & $150(57)$ \\
\hline \multicolumn{7}{|l|}{ Differentiation } \\
\hline Well, n (\%) & $11(10)$ & $|3|(16)$ & $9(28)$ & $4(20)$ & $7(27)$ & $30(\mathrm{II})$ \\
\hline Moderate, n (\%) & $52(46)$ & $494(59)$ & $14(44)$ & $8(40)$ & $55(46)$ & $102(39)$ \\
\hline Poor, n (\%) & $50(44)$ & $212(25)$ & $9(28)$ & $8(40)$ & $40(27)$ & $132(50)$ \\
\hline \multicolumn{7}{|l|}{ Pathological stage } \\
\hline I, n (\%) & $56(50)$ & $496(59)$ & $20(63)$ & II (55) & $39(6 I)$ & $127(48)$ \\
\hline II, n (\%) & $22(19)$ & $90(11)$ & I (3) & $2(10)$ & $16(3)$ & $36(14)$ \\
\hline III, n (\%) & $33(29)$ & $235(28)$ & II (34) & $7(35)$ & $42(33)$ & $97(37)$ \\
\hline IV, n (\%) & $2(2)$ & $16(2)$ & $0(-)$ & $0(-)$ & $5(3)$ & $4(2)$ \\
\hline \multicolumn{7}{|l|}{ Pathological subtype } \\
\hline AIS, n (\%) & $0(-)$ & $15(1.8)$ & $3(9.4)$ & $0(-)$ & I (I.0) & $9(3.4)$ \\
\hline MIA, n (\%) & $2(1.8)$ & $25(3.0)$ & $2(6.3)$ & $0(-)$ & $0(-)$ & $4(1.5)$ \\
\hline Lepidic, n (\%) & $5(4.4)$ & $92(11.0)$ & I (3.I) & $3(15.0)$ & $3(2.9)$ & $17(6.4)$ \\
\hline Acinar, n (\%) & $34(30.1)$ & $430(5 I .4)$ & $13(40.6)$ & $5(25.0)$ & $28(27.5)$ & $79(30.0)$ \\
\hline Papillary, n (\%) & $14(12.4)$ & $139(16.6)$ & $4(12.5)$ & $3(15.0)$ & $18(17.6)$ & $35(13.3)$ \\
\hline Micropapillary, n (\%) & $0(-)$ & $18(2.2)$ & $0(-)$ & $0(-)$ & I (I.0) & $2(0.8)$ \\
\hline Solid, n (\%) & $34(30.1)$ & $90(10.8)$ & $4(12.5)$ & $5(25.0)$ & $30(29.4)$ & 91 (34.5) \\
\hline IMA, n (\%) & $23(20.4)$ & $18(2.2)$ & $5(15.6)$ & $2(10.0)$ & $19(18.6)$ & $15(5.7)$ \\
\hline Other, n (\%) & I (0.9) & $10(1.2)$ & $0(-)$ & $2(10.0)$ & $2(2.0)$ & $12(4.5)$ \\
\hline
\end{tabular}

Note: Other includes enteric subtype and unknown.

Abbreviations: AIS, adenocarcinoma in situ; IMA, invasive mucinous adenocarcinoma; MIA, minimally invasive adenocarcinoma; WT, wild type. 


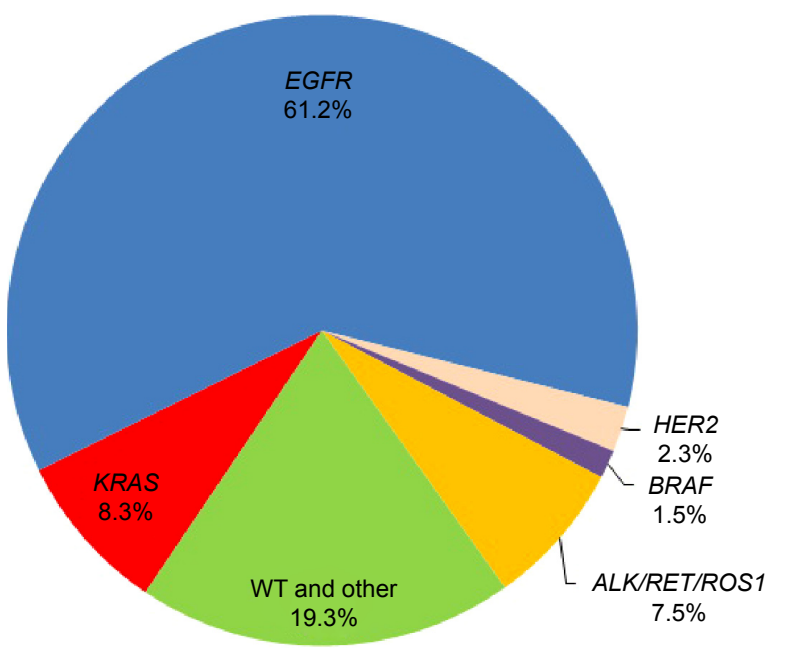

Figure I Frequency of gene mutations in I,368 patients with lung adenocarcinoma. Abbreviation: WT, wild type.

with $K R A S$ mutations had a concomitant mutation in $E G F R$, HER2, BRAF, or ALK/RET/ROS1.

\section{KRAS mutation subtypes}

Nine different subtypes of $K R A S$ mutation were identified, including five types of G12* mutations, two types of G13* mutations, and two types of Q61* mutations. G12C $($ GGT $\rightarrow$ TGT) was the most frequent amino acid substitution seen in this cohort, accounting for $33.6 \%$ of the patients followed by G12D (GGT $\rightarrow$ GAT) mutation $(23.9 \%), \mathrm{G} 12 \mathrm{~V}$ $($ GGT $\rightarrow$ GTT) mutation $(22.1 \%)$, and G12A $($ GGT $\rightarrow$ GCT) mutation $(7.1 \%)$. Seventy percent of patients $(79 / 113)$ harbored transversion mutations (G12A, G12C, G12V, G13C, Q61H) (Figure 2).

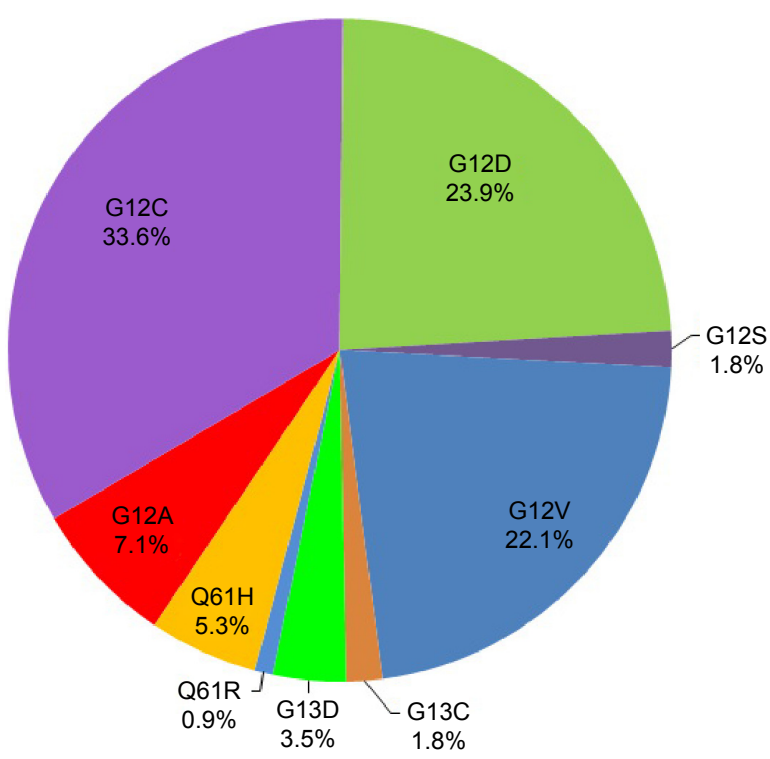

Figure 2 Frequency of KRAS mutation subtypes in II 3 KRAS mutation patients.

\section{KRAS mutation and clinicopathological variables}

In this study, $K R A S$ mutation was more frequently found in male patients (odds ratio 5.30; 95\% confidence interval (CI) 3.31-8.49; $P<0.001)$ and former/current smoke patients (odds ratio 5.58; 95\% CI 3.67-8.49; $P<0.001$ ). Tumors with $K R A S$ mutation were poorly differentiated (odds ratio 1.69; 95\% CI 1.15-2.50; $P=0.008)$. Among all the adenocarcinoma subtypes, invasive mucinous adenocarcinoma predominant $(20.4 \%$ vs $4.7 \%, P<0.001)$ and solid predominant (30.1\% vs $17.5 \%, P=0.004)$ were more frequent in $K R A S$ mutant patients compared with KRAS wide-type patients (Table 2).

\section{Survival analysis}

In all, 1,131 patients were involved in survival analysis, including 108 patients harboring KRAS mutation. Follow-up started from October 2007 to June 2015.

The follow-up time ranged from 1 to 88 months. The median RFS for all patients and KRAS mutant patients was 49 months (95\% CI 40-57 months) and 53 months (95\% CI 16-90 months), respectively. No statistical significance was found in RFS between patients with KRAS mutation

Table 2 Features of patients with lung adenocarcinoma harboring KRAS mutation

\begin{tabular}{|c|c|c|c|c|c|}
\hline & \multicolumn{2}{|c|}{$\begin{array}{l}\text { KRAS } \\
\text { mutation } \\
(\mathrm{n}=\mid \mathrm{I})\end{array}$} & \multicolumn{2}{|c|}{$\begin{array}{l}\text { KRAS WT } \\
(n=I, 255)\end{array}$} & \multirow[t]{2}{*}{$P$-value } \\
\hline & $\mathbf{n}$ & $\%$ & $\mathbf{n}$ & $\%$ & \\
\hline Sex & & & & & $P<0.00 I^{*}$ \\
\hline Male & 90 & 80 & 533 & 42 & \\
\hline Female & 23 & 20 & 722 & 58 & \\
\hline Age & & & & & $P=0.245$ \\
\hline$<60$ years & 63 & 56 & 628 & 50 & \\
\hline$\geq 60$ years & 50 & 44 & 627 & 50 & \\
\hline Smoker & & & & & $P<0.00 I^{*}$ \\
\hline Never & 34 & 30 & 886 & 71 & \\
\hline Former/current & 79 & 70 & 369 & 29 & \\
\hline Differentiation & & & & & $P=0.008^{*}$ \\
\hline Well/moderate & 63 & 56 & 854 & 68 & \\
\hline Poor & 50 & 44 & 401 & 32 & \\
\hline Pathological stage & & & & & $P=0.626$ \\
\hline $\mathrm{I} / \mathrm{II}$ & 78 & 69 & 838 & 67 & \\
\hline III/IV & 35 & 31 & 417 & 33 & \\
\hline IMA predominant & & & & & $P<0.001 *$ \\
\hline Yes & 23 & 20 & 59 & 5 & \\
\hline No & 90 & 80 & 1,196 & 95 & \\
\hline Solid predominant & & & & & $P=0.004^{*}$ \\
\hline Yes & 34 & 30 & 220 & 18 & \\
\hline No & 79 & 70 & $\mathrm{I}, 035$ & 82 & \\
\hline
\end{tabular}

Note: *Indicates statistical significance.

Abbreviations: IMA, invasive mucinous adenocarcinoma; WT, wild type. 

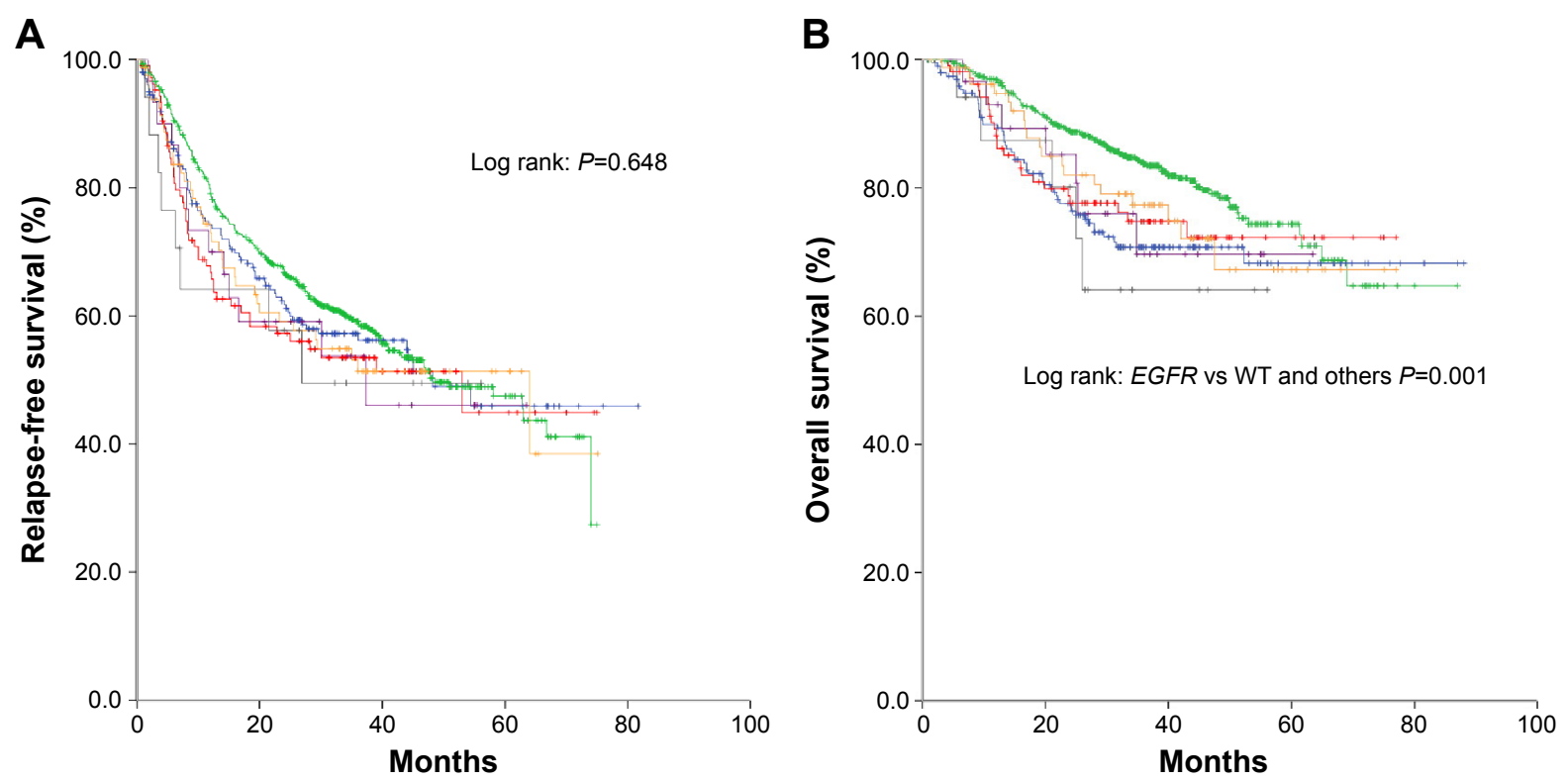

Mutations
$\neg$ WT and others $\neg$ KRAS $\neg$ EGFR $\neg$ HER2 $\neg$ BRAF $\neg$ ALK/RET/ROS1

Figure 3 Relapse-free survival (A) and overall survival (B) in all patients.

Note: Kaplan-Meier curve for relapse-free survival and overall survival in I, I3I patients with lung adenocarcinoma.

Abbreviation: WT, wild type.

and patients with other mutations (Figure 3A). Patients with $E G F R$ mutation lived longer than mutation wide type patients $(P=0.001)$. No statistical significance was found between patients with KRAS mutation and patients with other mutations in overall survival (Figure 3B). In multivariate analysis, former/current smoke patients (hazard ratio [HR] $1.32 ; 95 \%$ CI $1.09-1.58 ; P=0.004$ ), advanced stage (HR 3.36 ; 95\% CI 2.76-4.08; $P<0.001)$, and poor differentiation in tumor (HR 3.07; 95\% CI 2.09-4.50; $P<0.001$ ) were risk factors in recurrence. The occurrence of KRAS mutation in patients did not mean an unfavorable prognosis; nevertheless, male patients, patients with advanced stage, or patients with poor differentiation in tumor lived shorter than others (Table 3).

\section{Survival analysis of KRAS subtypes}

In 108 qualified patients with KRAS mutation, the median RFS was 53 months, while the median overall survival was not reached. No significant difference was found in survival among patients with different KRAS point mutations. Sex (Figure 4A and B), age (Figure 4C and D), and smoking status (Figure 4E and F) did not affect survival time either. Those patients with advanced stage or whose tumor was poorly differentiated got an earlier recurrence and shorter survival (Table 3). Mutation sites in KRAS did not affect the prognosis (Figure 5A and B). There was no difference in survival between patients with $K R A S$ transition mutations and patients with $K R A S$ transversion mutations (Figure $5 \mathrm{C}$ and $\mathrm{D}$ ). When the KRAS mutation was divided into two groups (hydrophobic

Table 3 Univariate and multivariate survival analysis of I, I3I patients with lung adenocarcinoma

\begin{tabular}{|c|c|c|c|c|c|c|c|c|c|c|c|c|c|}
\hline \multirow[t]{3}{*}{ Variable } & \multirow[t]{3}{*}{ Category } & \multicolumn{6}{|c|}{ RFS analysis } & \multicolumn{6}{|c|}{ OS analysis } \\
\hline & & \multicolumn{3}{|c|}{ Univariate } & \multicolumn{3}{|c|}{ Multivariate } & \multicolumn{3}{|c|}{ Univariate } & \multicolumn{3}{|c|}{ Multivariate } \\
\hline & & HR & $95 \% \mathrm{Cl}$ & $P$-value & HR & $95 \% \mathrm{Cl}$ & $P$-value & HR & $95 \% \mathrm{Cl}$ & $P$-value & HR & $95 \% \mathrm{Cl}$ & $P$-value \\
\hline Age, years & $\geq 60 /<60$ & 1.03 & $(0.86-1.23)$ & 0.77 & NA & NA & NA & 1.18 & $(0.91-1.53)$ & 0.219 & 1.30 & $(0.99-1.69)$ & 0.052 \\
\hline Sex & Male/female & 1.60 & $(1.33-1.91)$ & $<0.00 \mathrm{I}^{*}$ & NA & NA & NA & 1.77 & $(1.36-2.30)$ & $<0.001 *$ & 1.34 & $(1.02-1.75)$ & $<0.033 *$ \\
\hline Smoker & Yes/no & 1.76 & $(1.47-2.11)$ & $<0.001 *$ & 1.32 & $(1.09-1.58)$ & $0.004^{*}$ & I.75 & $(1.34-2.27)$ & $<0.00 I^{*}$ & NA & NA & NA \\
\hline $\begin{array}{l}\text { Pathological } \\
\text { stage }\end{array}$ & III, IV/I, II & 4.31 & $(3.59-5.17)$ & $<0.001 *$ & 3.36 & $(2.76-4.08)$ & $<0.00 I^{*}$ & 4.06 & $(3 . \mid I-5.3 I)$ & $<0.00 I^{*}$ & 2.94 & $(2.2 I-3.92)$ & $<0.00 I^{*}$ \\
\hline \multirow[t]{2}{*}{ Differentiation } & Moderate/well & 2.86 & $(2.00-4.09)$ & $<0.00 I^{*}$ & 2.24 & $(1.56-3.22)$ & $<0.001 *$ & 3.73 & $(1.95-7.15)$ & $<0.001 *$ & 2.78 & $(1.44-5.37)$ & $0.002^{*}$ \\
\hline & Poor/well & 5.91 & $(4.10-8.51)$ & $<0.001 *$ & 3.07 & $(2.09-4.50)$ & $<0.001 *$ & 9.94 & $(5.21-18.99)$ & $<0.001 *$ & 5.17 & $(2.64-10.12)$ & $<0.00 I^{*}$ \\
\hline KRAS mutation & Mutation/WT & 1.18 & $(0.88-1.60)$ & 0.266 & NA & NA & NA & 1.26 & $(0.83-1.92)$ & 0.271 & NA & NA & NA \\
\hline
\end{tabular}

Note: *Indicates statistical significance.

Abbreviations: $\mathrm{Cl}$, confidence interval; $\mathrm{HR}$, hazard ratio; NA, not applicable; OS, overall survival; RFS, relapse-free survival; WT, wild type. 
A

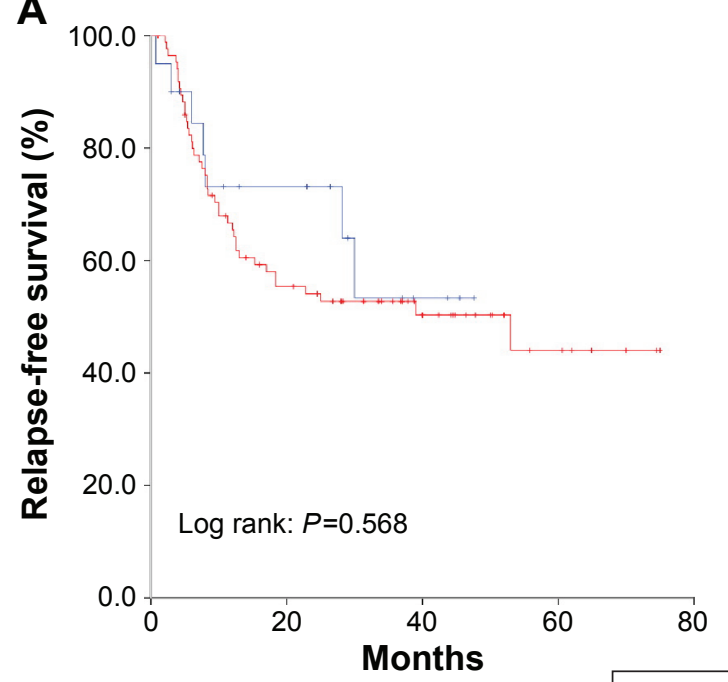

B

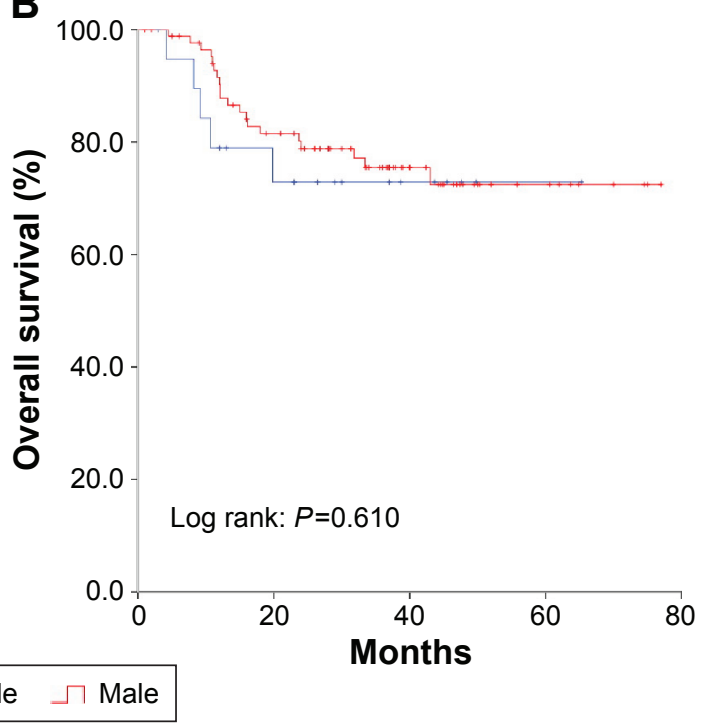

C
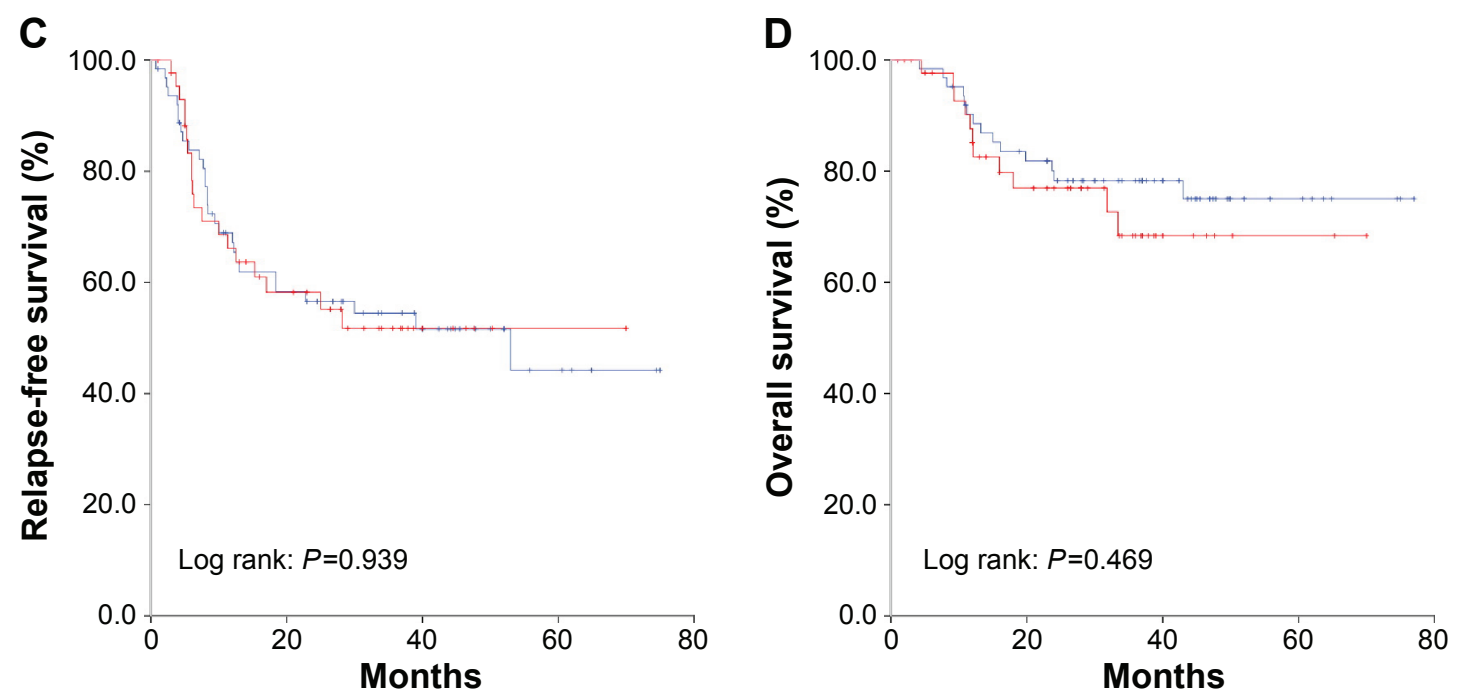

E

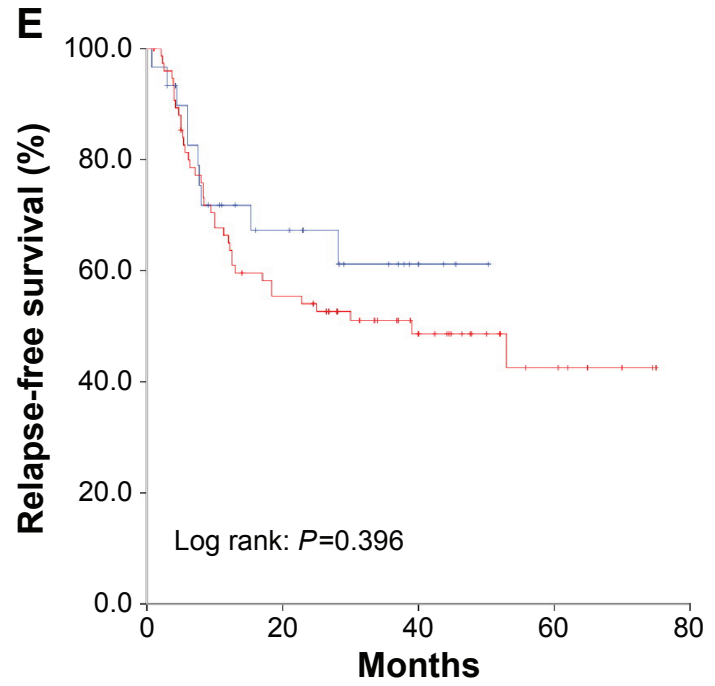

$\neg \geq 60$ years of age

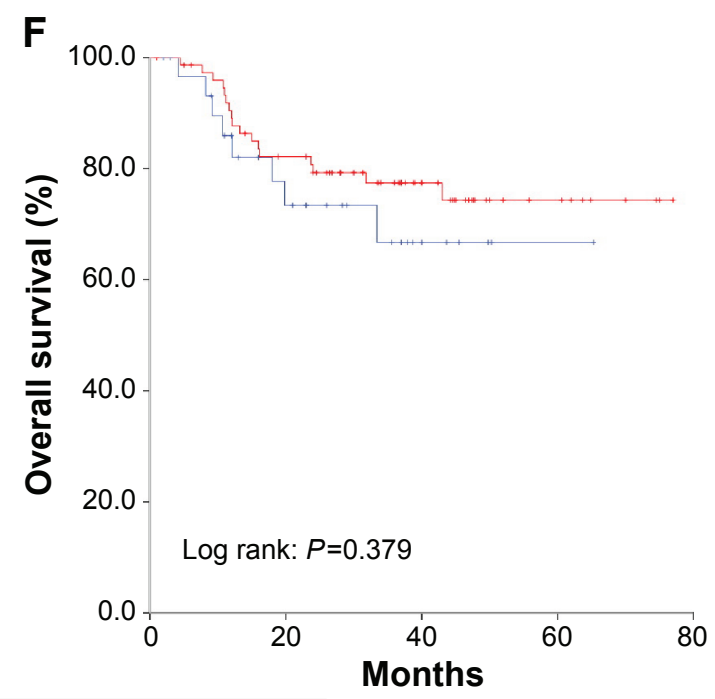

$\neg$ Never smoker $\neg$ Former/current smoker

Figure 4 Relapse-free survival and overall survival of sex (A and $\mathbf{B})$, age (C and $\mathbf{D})$, and smoking status (E and $\mathbf{F})$ in KRAS mutation patients. 
A

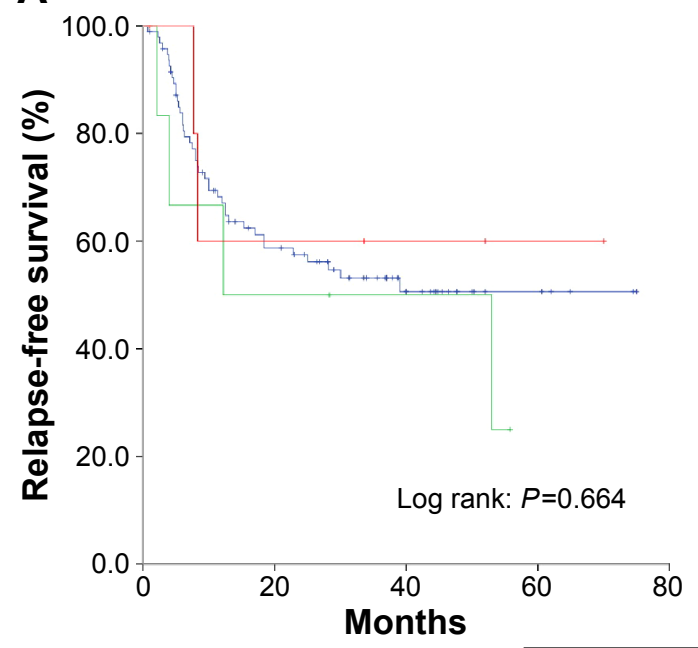

\section{B}

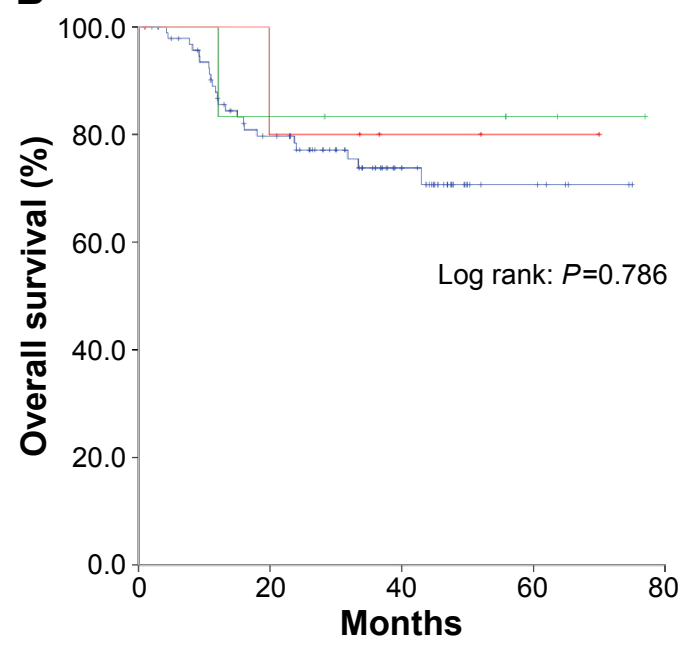

C

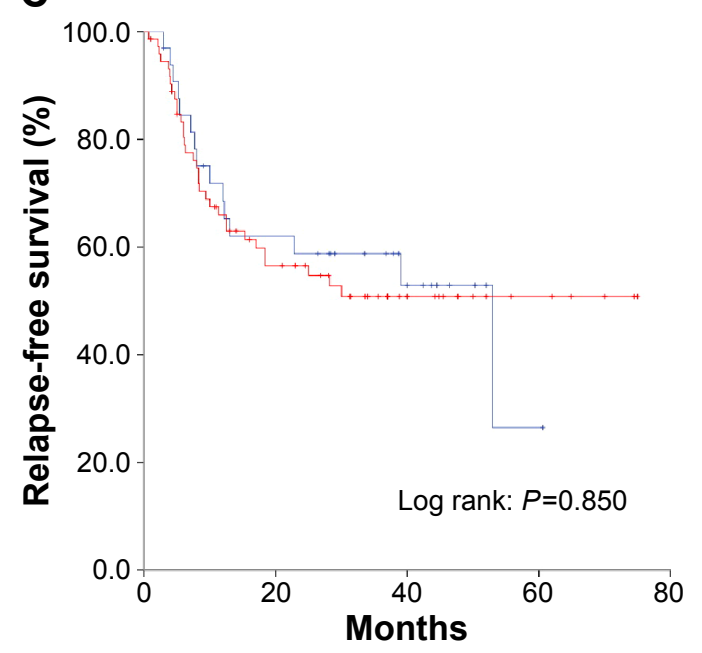

D

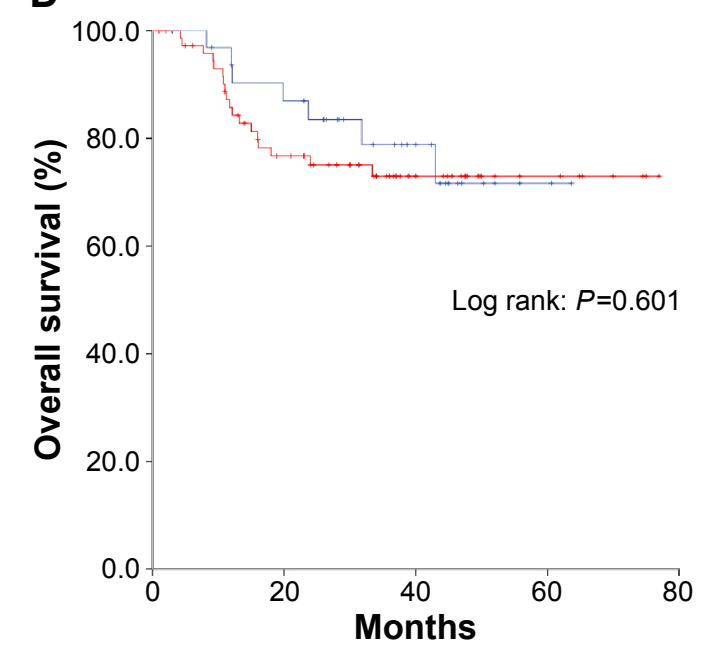

E

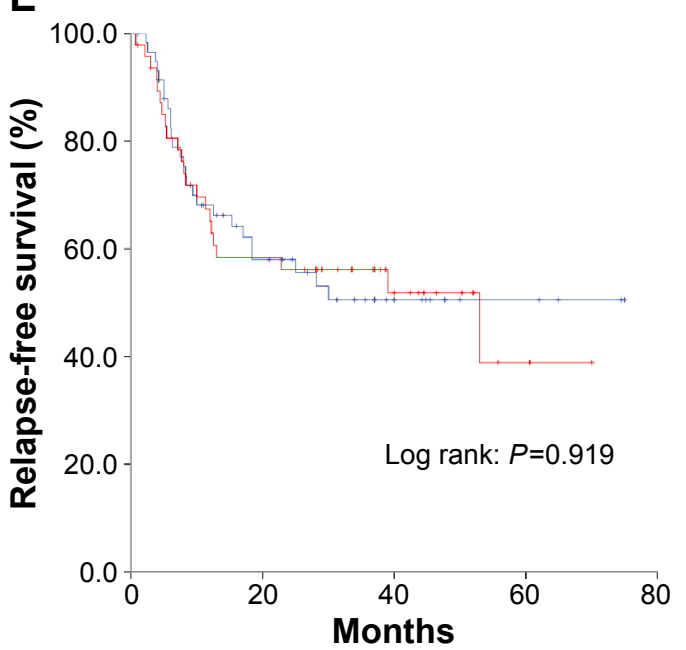

F

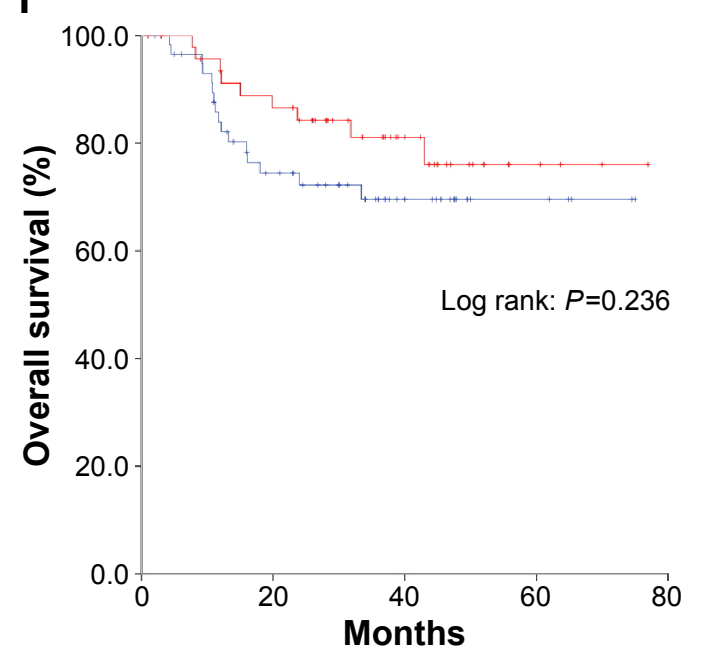

$$
\neg \text { Hydrophobic } \neg \text { Hydrophilic }
$$

Figure 5 Relapse-free survival and overall survival of codon (A and $\mathbf{B})$, transition/transversion $(\mathbf{C}$ and $\mathbf{D})$, and hydrophobic/hydrophilic $(\mathbf{E}$ and $\mathbf{F})$ subtypes in KRAS mutation patients. 
alterations [G12C and G12V] and hydrophilic alterations [such as G12D]), no significant difference was found in either RFS or overall survival (Figure 5E and F). Multivariate analysis revealed that advanced stage was the only risk factor that indicated shorter recurrence (HR 2.66; 95\% CI 1.51-4.70; $P=0.001$ ), and smoking status, sex, age, or different $K R A S$ subtypes did not affect the outcome (Table 3).

\section{Discussion}

In the present study, KRAS mutation was detected in $8.3 \%$ $(113 / 1,368)$ of lung adenocarcinoma patients in Chinese population. This number was relatively lower compared with the data from Asian population. European population, however, had a much higher mutation rate of $K R A S$ gene. ${ }^{9,10}$ Besides, KRAS mutation was predominantly found in male patients and smokers. KRAS mutation and other driver mutations, such as EGFR, HER2, and $B R A F$, were mutually exclusive. Poor differentiation appeared in almost half of the tumors with $K R A S$ mutation, compared with less than a third of the non-KRAS mutant tumors. This suggested that $K R A S$ mutation probably led to an unfavorable prognosis. Meanwhile, the proportion of invasive mucinous adenocarcinoma predominant subtype and solid predominant subtype was significantly higher in $K R A S$ mutation. Considering these two subtypes, especially the solid predominant subtype as indicators of poor prognosis, KRAS mutation might be a late event in lung cancer. Keohavong et $\mathrm{al}^{19}$ reported that specific $K R A S$ point mutations (such as G12V) were associated with poorer outcome. Recently, a meta-analysis which synthesized 12 randomized trials also confirmed that KRAS mutations were related to poor survival benefit for NSCLC. ${ }^{14}$ Our data, however, did not show this pattern in survival analysis.

$K R A S$ point mutation in human cancers takes place primarily at residues $\mathrm{G} 12, \mathrm{G} 13$, or Q61, with single amino acid substitution. In lung cancer, KRAS mutation occurs predominantly at residues G12 or G13., ${ }^{7,12}$ Mutations can be further divided into transversion and transition subtypes according to its biological features and prognostic impact. Riely's discovery of different smoking status leading to a different $K R A S$ point mutation profile suggested that there might be an explicit mechanism of tobacco carcinogens on KRAS mutation. ${ }^{12}$ Conflicting data also arouse the suspicion on cigarette smoke. ${ }^{20}$ In animal experiments, scientists revealed quite a similar pattern in lung tumors from mice treated with $\mathrm{BaP}, 5$-methylchrysene, and benzo[b] fluoranthene, which are carcinogens commonly found in tobacco smoke. ${ }^{21}$ However, detailed analysis showed that the methylguanine pathway of nicotine-derived nitrosamine ketone, also known as 4-(methylnitrosamino)-1-(3-pyridyl)1-butanone (NNK) metabolic results in a high percentage of $\mathrm{GGT} \rightarrow \mathrm{GAT}$ mutations (transition) in codon 12 of $K R A S,{ }^{22}$ while pyridyloxobutylation leads to more $\mathrm{G} \rightarrow \mathrm{T}$ mutation (transversion) in codon $12 .{ }^{23}$ The relative significance of these pathways in human lung cells remains unknown, and further investigations are needed.

Remarkably, Ihle et $\mathrm{al}^{24}$ classified $K R A S$ mutation into hydrophobic (G12C and G12V) and hydrophilic alteration (G12D) subgroups. In vitro experiments demonstrated different patterns of downstream signal transduction and response to targeted therapies between these two subgroups. Specifically, mutant G12C or G12V KRAS protein would activate Ral signaling and decrease growth factor-dependent Akt activation, while mutant G12D KRAS protein would predominantly activate the PI3K and MEK/ERK pathways. Such results could be partially explained by the changes in spatial conformation after mutation. Finally, tumor behavior and drug sensitivity varied in different subgroups of $K R A S$ mutation. ${ }^{25}$ Although in general, KRAS codon 12 point mutation was proven to indicate a poor prognosis, a more specific classification was required to assess its biological malignancy and therapeutic efficacy. In clinical practice, individualized treatment was recommended concerning patients harboring $K R A S$ mutation.

Nowadays, scientists also focus on $K R A S$ mutation cooccurring with other gene mutations. Lung adenocarcinomas harboring $S T K 11 / L K B 1$, TP53, or $C D K N 2 A / B$ mutation as well as $K R A S$ mutation identified distinct clinicopathological features and different therapeutic responses. ${ }^{26}$ This insight would direct the treatment strategy not only pointing at a single $K R A S$ gene, but a set of related genes.

There are no known direct $K R A S$ targeted agents. Survival of patients harboring $K R A S$ mutation is almost disappointing with or without chemotherapy, targeted therapy, or other treatment. Some researchers came to a conclusion that $K R A S$ status might indicate poor response to EGFR TKIs. ${ }^{27-31}$ This evidence should be considered with caution due to the small numbers involved in the analyses. Meanwhile, meta-analysis showed that $K R A S$ mutations are highly specific negative predictors of response to single-agent EGFR TKIs in advanced NSCLC. ${ }^{32}$ Limited success was developed on the treatment of $K R A S$ mutation in the past decade; however, delightful consequences emerged.

A Phase II randomized trial showed that selumetinib plus docetaxel had promising efficacy, albeit with a higher number of adverse events than with docetaxel alone, in previously 
treated advanced KRAS-mutant NSCLC. ${ }^{33}$ Patients in the experiment group had a longer progression-free survival and $37 \%$ of them had an objective response.

By blocking one of the most important downstream pathways of $K R A S$, an MEK1/2 inhibitor (AZD6244) combined with cisplatin showed an antitumor effect in $K R A S$-dependent lung cancer cells and animal models. ${ }^{34}$ Clinical studies of applications of MEK1/2 inhibitors in cisplatin-based chemotherapy for lung cancer patients harboring $K R A S$ mutation are urgently required.

Ostrem et $\mathrm{al}^{35}$ developed a small molecule that irreversibly bound to a common oncogenic mutant, K-Ras (G12C), while it had no effect on the wild-type protein. Once bound, the inhibitor-KRAS compound subverted the native nucleotide preference to favor GDP over GTP and therefore impaired binding to the downstream Raf protein. If it is possible to make this molecule available in clinics in the future, it will make $K R A S$ mutation targetable and may bring benefit to patients.

Furthermore, oncogenic drivers, such as mutated KRAS can be targeted with synthetic lethality approaches. ${ }^{36}$ Although synthetic lethality till now is a concept and has not yet been applied in clinical practice, it is a promising rationale and will ultimately become a therapeutic approach.

\section{Conclusion}

In Chinese population, we identified $K R A S$ mutation in $8.3 \%$ $(113 / 1,368)$ of the patients with lung adenocarcinoma. KRAS mutation defines a molecular subset of lung adenocarcinoma with unique clinicopathological features. KRAS mutations were more frequent in male patients, former/current smokers, and patients harboring $K R A S$ mutations who showed poor differentiation in tumor tissues.

\section{Acknowledgments}

This work was funded by the National Natural Science Foundation of China (81330056, 81401886, 81401891, 81422029,81472173 , and 81372525), the Key Project of Science and Technology Commission of Shanghai Municipality (JGGG1302), and Shen-Kang Center Project (SKMB1201).

\section{Author contributions}

Haiquan Chen is the guarantor of the manuscript and contributed to conception and study design, analysis of data, and review and revision of the manuscript. Difan Zheng, Rui Wang, and Yang Zhang contributed to conception and study design, acquisition and analysis of data, and writing and revision of the manuscript. Yunjian Pan and Xinghua Cheng contributed to acquisition of data and writing and revision of the manuscript. Chao Cheng and Xuxia Shen contributed to analysis of data and revision of the manuscript. Shanbo Zheng, Hang Li, Ranxia Gong, and Yuan Li: contributed to acquisition of data and revision of the manuscript. Yihua Sun contributed to conception and study design, and review and revision of the manuscript. All authors gave final approval of the version to be published, and agree to be accountable for all aspects of the work.

\section{Disclosure}

The authors report no conflicts of interest in this work.

\section{References}

1. Torre LA, Bray F, Siegel RL, Ferlay J, Lortet-Tieulent J, Jemal A Global cancer statistics, 2012. CA Cancer J Clin. 2015;65(2):87-108.

2. Ettinger DS, Wood DE, Akerley W, et al. Non-small cell lung cancer, version 6.2015. J Natl Compr Canc Netw. 2015;13(5):515-524.

3. Tsao MS, Sakurada A, Cutz JC, et al. Erlotinib in lung cancer - molecular and clinical predictors of outcome. $N$ Engl J Med. 2005;353(2): 133-144.

4. Maemondo M, Inoue A, Kobayashi K, et al. Gefitinib or chemotherapy for non-small-cell lung cancer with mutated EGFR. NEngl J Med. 2010; 362(25):2380-2388

5. Shaw AT, Kim DW, Nakagawa K, et al. Crizotinib versus chemotherapy in advanced ALK-positive lung cancer. N Engl J Med. 2013; 368(25):2385-2394.

6. Solomon BJ, Mok T, Kim DW, et al. First-line crizotinib versus chemotherapy in ALK-positive lung cancer. N Engl J Med. 2014;371(23): 2167-2177.

7. Roberts PJ, Stinchcombe TE. KRAS mutation: should we test for it, and does it matter? J Clin Oncol. 2013;31(8):1112-1121.

8. Roberts PJ, Der CJ. Targeting the Raf-MEK-ERK mitogen-activated protein kinase cascade for the treatment of cancer. Oncogene. 2007;26: 3291-3310.

9. Yu HA, Sima CS, Shen R, et al. Prognostic impact of KRAS mutation subtypes in 677 patients with metastatic lung adenocarcinomas. J Thorac Oncol. 2015;10(3):431-437.

10. Arrieta O1, Cardona AF, Martín C, et al. Updated frequency of EGFR and KRAS mutations in non-small-cell lung cancer in Latin America: The Latin-American Consortium for the Investigation of Lung Cancer (CLICaP). J Thorac Oncol. 2015;10(5):838-843.

11. Mao C, Qiu LX, Liao RY, et al. KRAS mutations and resistance to EGFR-TKIs treatment in patients KRAS mutations in NSCLC with non-small cell lung cancer: a meta-analysis of 22 studies. Lung Cancer. 2010;69:272-278.

12. Riely GJ, Kris MG, Marks JL, et al. Frequency and distinctive spectrum of KRAS mutations in never smokers with lung adenocarcinoma. Clin Cancer Res. 2008;14(18):5731-5734.

13. Slebos RJ, Kibbelaar RE, Dalesio O, et al. K-ras oncogene activation as a prognostic marker in adenocarcinoma of the lung. $N$ Engl J Med. 1990;323:561-565.

14. Ying M, Zhu XX, Zhao Y, Li DH, Chen LH. KRAS mutation as a biomarker for survival in patients with non-small cell lung cancer, a meta-analysis of 12 randomized trials. Asian Pac J Cancer Prev. 2015; 16(10):4439-4445.

15. Sun Y, Ren Y, Fang Z, et al. Lung adenocarcinoma from East Asian never-smokers is a disease largely defined by targetable oncogenic mutant kinases. J Clin Oncol. 2010;28:4616-4620. 
16. Wang R, Pan Y, Li C, et al. The use of quantitative real-time reverse transcriptase PCR for 5' and 3' portions of ALK transcripts to detect ALK rearrangements in lung cancers. Clin Cancer Res. 2012; 18:4725-4732.

17. Pan Y, Zhang Y, Li Y, et al. ALK, ROS1 and RET fusions in 1139 lung adenocarcinomas: a comprehensive study of common and fusion pattern-specific clinicopathologic, histologic and cytologic features. Lung Cancer. 2014;84(2):121-126.

18. Rui W, Lei W, Yuan L, et al. FGFR1/3 tyrosine kinase fusions define a unique molecular subtype of non-small cell lung cancer. Clin Cancer Res. 2014;20(15):4107-4114.

19. Keohavong P, DeMichele MA, Melacrinos AC, et al. Detection of K-ras mutations in lung carcinomas: relationship to prognosis. Clin Cancer Res. 1996;2:411-418.

20. Dogan S, Shen R, Ang DC, et al. Molecular epidemiology of EGFR and KRAS mutations in 3,026 lung adenocarcinomas: higher susceptibility of women to smoking-related KRAS-mutant cancers. Clin Cancer Res. 2012;18(22):6169-6177.

21. Nesnow S, Ross JA, Mass MJ, Stoner GD. Mechanistic relationships between DNA adducts, oncogene mutations, and lung tumorigenesis in strain A mice. Exp Lung Res. 1998;24:395-405.

22. Hecht SS. Biochemistry, biology, and carcinogenicity of tobaccospecific N-nitrosamines. Chem Res Toxicol. 1998;11:559-603.

23. Ronai ZA, Gradia S, Peterson LA, Hecht SS. G to A transitions and $\mathrm{G}$ to $\mathrm{T}$ transversions in codon 12 of the Ki-ras oncogene isolated from mouse lung tumors induced by 4-(methylnitrosamino)-1-(3-pyridyl)-1butanone (NNK) and related DNA methylating and pyridyloxobutylating agents. Carcinogenesis. 1993;14:2419-2422.

24. Ihle NT, Byers LA, Kim ES, et al. Effect of KRAS oncogene substitutions on protein behavior: implications for signaling and clinical outcome. J Natl Cancer Inst. 2012;104(3):228-239.

25. Garassino MC, Marabese M, Rusconi P, et al. Different types of K-Ras mutations could affect drug sensitivity and tumour behaviour in nonsmall-cell lung cancer. Ann Oncol. 2011;22(1):235-237.

26. Skoulidis F, Byers LA, Diao L, et al. Co-occurring genomic alterations define major subsets of KRAS - mutant lung adenocarcinoma with distinct biology, immune profiles, and therapeutic vulnerabilities. Cancer Discov. 2015;5:860-877.
27. Pao W, Wang TY, Riely GJ, et al. KRAS mutations and primary resistance of lung adenocarcinomas to gefitinib or erlotinib. PLoS Med. 2005;2:e17.

28. Han SW, Kim TY, Jeon YK, et al. Optimization of patient selection for gefitinib in non-small cell lung cancer by combined analysis of epidermal growth factor receptor mutation, K-ras mutation, and Akt phosphorylation. Clin Cancer Res. 2006;12:2538-2544.

29. Felip E, Rojo F, Reck M, et al. A phase II pharmacodynamic study of erlotinib in patients with advanced non-small cell lung cancer previously treated with platinum-based chemotherapy. Clin Cancer Res. 2008; 14:3867-3874.

30. Miller VA, Riely GJ, Zakowski MF, et al. Molecular characteristics of bronchioloalveolar carcinoma and adenocarcinoma, bronchioloalveolar carcinoma subtype, predict response to erlotinib. J Clin Oncol. 2008;26:1472-1478.

31. Roberts PJ, Stinchcombe TE, Der CJ, Socinski MA. Personalized medicine in non-small-cell lung cancer: Is KRAS a useful marker in selecting patients for epidermal growth factor receptor-targeted therapy? J Clin Oncol. 2010;28:4769-4777.

32. Linardou H, Dahabreh IJ, Kanaloupiti D, et al. Assessment of somatic k-RAS mutations as a mechanism associated with resistance to EGFRtargeted agents: A systematic review and meta-analysis of studies in advanced non-small-cell lung cancer and metastatic colorectal cancer. Lancet Oncol. 2008;9:962-972.

33. Janne PA, Shaw AT, Pereira JR, et al. Selumetinib plus docetaxel for KRAS-mutant advanced non-small-cell lung cancer: a randomised, multicentre, placebo-controlled, phase 2 study. Lancet Oncol. 2013; 14(1):38-47.

34. Kim EY, Kim A, Kim SK, Chang YS. AZD6244 inhibits cisplatininduced ERK1/2 activation and potentiates cisplatin-associated cytotoxicity in K-ras G12D reclinical models. Cancer Lett. 2015; 358(1):85-91.

35. Ostrem JM, Peters U, Sos ML, Wells JA, Shokat KM. K-Ras (G12C) inhibitors allosterically control GTP affinity and effector interactions. Nature. 2013;503(7477):548-551.

36. McLornan DP, List A, Mufti GJ. Applying synthetic lethality for the selective targeting of cancer. $N$ Engl J Med. 2014;371(18):1725-1735. 


\section{Supplementary material}

Table SI Primers used in this study

Primers for detecting KRAS mutation

\section{Target \\ KRAS exon 2-3}

Primers for detecting EGFR mutation Target

EGFR exon 18-22

Primers for detecting HER2 mutation

Target

HER2 exon |8-2|

Primers for detecting BRAF mutation

Target

BRAF exon $1 \mathrm{I}-15$
Forward primer $\left(5^{\prime}>>3^{\prime}\right)$

AGGCCTGCTGAAAATGACTG

Forward primer $\left(5^{\prime}>>3^{\prime}\right)$

TGAAGGCTGTCCAACGAATG

Forward primer $\left(5^{\prime}>>3^{\prime}\right)$

CCСTCTGACGTCCATCATCT

Forward primer $\left(5^{\prime}>>3^{\prime}\right)$

TCAGAAGACAGGAATCGAATGA
Reverse primer $\left(5^{\prime}>>3^{\prime}\right)$

TGGTGAATATCTTCAAATGATTTAGT

Reverse primer $\left(5^{\prime}>>3^{\prime}\right)$

AGGCGTTCTCCTTTCTCCAG

Reverse primer $\left(5^{\prime}>>3^{\prime}\right)$

GCAGGGTCTGGACTGAAGAA

Reverse primer $\left(5^{\prime}>>3^{\prime}\right)$

GATGACTTCTGGTGCCATCC

\section{Publish your work in this journal}

OncoTargets and Therapy is an international, peer-reviewed, open access journal focusing on the pathological basis of all cancers, potential targets for therapy and treatment protocols employed to improve the management of cancer patients. The journal also focuses on the impact of management programs and new therapeutic agents and protocols on patient perspectives such as quality of life, adherence and satisfaction. The manuscript management system is completely online and includes a very quick and fair peer-review system, which is all easy to use. Visit http://www.dovepress.com/testimonials.php to read real quotes from published authors.

\footnotetext{
Submit your manuscript here: http://www.dovepress.com/oncotargets-and-therapy-journal
} 